\title{
Pure Honey a potent fertility booster: Activities of Honey on sperm parameters in young adult rats.
}

\author{
${ }^{1,2}$ Igbokwe V.U., ${ }^{1}$ Gege-Adebayo G.I., and Ogbadu Samuel \\ Department of Physiology, College of Medicine, Bingham University, Karu, Nasarawa State \\ Department of Physiology, College of Medicine, Usmanu Danfodiyo University Sokoto, Sokoto State
}

\begin{abstract}
Honey is a natural product of bees containing numerous nutrients that have significant benefits to human race. These benefits stretch across from its antiseptic, antibacterial, and wound healing properties to its possible sex boosting properties. Due to environmental, nutritional, behavioral and physiological factors, male infertility has become an ubiquitous issue over the world.

This study therefore investigates the effect of honey on some sperm parameters in rats. Eighteen adult male rats weighing $130 \mathrm{~g}-165 \mathrm{~g}$ were used for this study. They were randomly divided into three groups with group A serving as the control; group B served as the standard group treated with a standard drug $(622 \mathrm{mg} / \mathrm{kg})$; and group $C$ was treated with honey ( $1 \mathrm{ml}$ of honey per $100 \mathrm{~g}$ of body weight). They were treated for 65 days thereafter, the sperm count, motility, and morphology were evaluated.

The mean value of the sperm count of group C rats $\left(130.5 \pm 7.50 \times 10^{6} / \mathrm{ml}\right)$ was significantly higher than the group $B$ rats $\left(104.3 \pm 3.48 \times 10^{6} / \mathrm{ml}\right)$ and the group A rats $\left(93.5 \pm \times 10^{6} / \mathrm{ml}\right)$ at $p<0.05$. The sperm motility of group $C$ animals, $85 \pm 5.0 \%$, was significantly higher $(p<0.05)$ when compared to group $B$ animals, $33.3 \pm$ $3.33 \%$, and group A animals, $75 \pm 5.0 \%$. The percentage of abnormal sperm was reduced in group C rats (5\%) as compared to group $B(8.3 \%)$ and group A rats $(10 \%)$. This study showed that honey increases the sperm count, the sperm motility and improves the sperm morphology. Thus it serves as a potential fertility booster in experimental animals.
\end{abstract}

Keywords: Fertility, Honey, Sperm morphology, Sperm motility, Sperm count,

\section{Introduction}

Reproduction and childbirth are part of the central themes of life, occurring when planned and wished in many but not all cases (Johansson et al., 2011). The prevalence of infertility in men varies between countries mainly due to variations in lifestyle factors, the time interval between the age where sexuality is initiated and the age where first pregnancy is desired, and of course, the prevalence of sexually transmitted diseases (STDs) (Nygren and Zegers-Hochschild, 2008). Boivin et al., (2007) following their study of world population reported that 72.4 million people were infertile and of these 40.5 million people were seeking infertility medical care. Female factors were responsible for $35 \%$ of infertile cases, while the male factors accounted for $30 \%$ of infertile cases. Both the male and female factors were responsible for $20 \%$ of infertile cases and unexplained causes of infertility accounts for $15 \%$ of cases (Rubenstein and Brannigan, 2011). Over the years, curative measures have been applied to curb infertility, these measures include the use of herbs (e.g. Alfafa, Kelp, or Mandrakes used by Rachel in the Bible), vitamin supplements, drugs (e.g Metformin, Spermomax, Manix) and medical procedures \{e.g. in vitro fertilization and embryo transfer (IVF-ET) and gamete intrafallopian transfer (GIFT)\} (Carangelo, 2002).

Honey is the natural product of bees (Honey bees) formed from the nectar collected from flowering vegetation (Mahaneem et al., 2010). It is an alkaline forming food and contains ingredients similar to those found in fruits, which become alkaline in the digestive system (Bradley, 2010). From ancient times, honey has been used as both a natural sweetener and a healing agent (National Honey Board, 2012).

Honey is a high nutrient source. It contains sugars such as glucose and fructose, as well as minerals like magnesium, potassium, calcium, sodium chloride, sulphur, iron, zinc, phosphates and vitamins $\mathrm{B}_{1}, \mathrm{~B}_{2}, \mathrm{C}, \mathrm{B}_{6}, \mathrm{~B}_{5}$ and $\mathrm{B}_{3}$ (Estevinho et al., 2008; Syazana et al., 2011). In recent years, scientific support is beginning to emerge confirming the beneficial effects of honey on certain medical and surgical conditions. Honey has been shown to have biological properties such as antiseptic, antibacterial and antifungal (Tan et al., 2009), anti-inflammatory and antioxidant properties (Viuda-Martos et al., 2008) and immunomodulatory effects (Mandal and Mandal, 2011). It has also wound healing properties (Green, 1988).

Male reproductive performance, particularly sperm count, can be affected by environmental (Sikka and Wang, 2008), genetic (Skakkebaek et al., 1994), behavioural and physiological factors. Honey, also known as an aphrodisiac, has been reported to increase sperm count, testosterone and libido level (Austin, 2011). It contains glucose and fructose, which may be used by the body to obtain energy, thereby improving sexual virility (Bradley, 2010). According to the British Broadcasting Corporation (BBC), Nigerian honey is raw, un- 
pasteurized, and is almost crunchy with sugar crystals. Although large amounts of honey are produced in Nigeria, packaging and distribution are disorganized and the Nigerian honey has not well been researched into. Often the place to buy the best honey is on the side of the road.

Previous work done by Syazana et al., (2011) on the effect of gelam honey on sperm quality and testis of rats show no significant differences in the weight, width and length of testes between the groups, but showed significant increase in sperm count and improvement of sperm motility in the honey treated group than in the control group. Also, work done in Palestine by Abdul-Ghani et al., (2008) on the effect of Palestinian honey on spermatogenesis in rat showed that there was increase in weight of the epididymis and epididymal sperm count by $37 \%$ after administration of honey.

The effect of honey on sperm parameters such as sperm count, morphology and motility are further investigated in this study with the Nigerian honey. It is hoped that honey might be a booster of low sperm count and motility and thus of use in treatment of male infertility

\section{a. REAGENTS}

\section{Materials And Method}

Honey was purchased from Wiloff Global Venture, Lagos, Nigeria. Manix herbal capsule from Workhardt Limited, India was also purchased.

\section{b. PREPARATION OF DRUGS}

Ten capsules of Manix drug was dissolved in $100 \mathrm{ml}$ of distilled water to give a concentrated solution of $6220 \mathrm{mg} / 100 \mathrm{ml}$ of drug solution. This was administered to the rats according to their body weights, i.e $1 \mathrm{ml} / 100 \mathrm{~g}$ bodyweight.

\section{c. METHOD}

A total of eighteen adult male wistar rats, (4-6 weeks old) were obtained from the National Institute for Veterinary Research, Plateau State, Nigeria. The rats were housed in cages and kept at the Bingham University Animal house, Nasarawa State, Nigeria. They were fed with standard rat pellet and allowed to acclimatize for a period of two weeks. The duration of the study was 65 days.

\section{d. TREATMENT REGIME}

The rats were divided randomly into three groups. These were the control group, the standard group and the honey treated group.

Group 1: This was the control group, it had six rats, and they received a daily dose of $1.0 \mathrm{ml} / 100 \mathrm{~g}$ body weight of normal saline $(0.9 \%)$ orally for a period of 65 days according to Syazana et al., (2011). Group 2: The standard group had six rats, and they were given $622 \mathrm{mg} / \mathrm{kg}$ body weight of manix for 65 days. Group 3 was the honey treated group. It also contained six rats that received a daily administration of $1.0 \mathrm{ml} / 100 \mathrm{~g}$ body weight of honey orally for 65 days (Syazana et al., 2011). The body weights were monitored weekly.

\section{e. SPERM COUNT DETERMINATION}

Methods of Selmanoğlu et al., (2009) and Mahaneem et al., (2010) were used to analyze sperm count. The cauda epididymis was dissected and minced in $1 \mathrm{ml}$ of normal saline $(0.9 \%)$, then filtered using a nylon mesh. The suspension was then fixed in normal saline and spermatozoa were counted using the Neubauer hematocytometer chamber.

\section{f. SPERM MOTILITY}

The method of Biswas et al., (2002) was used with a minor modification. The content of the vas deferens was collected with the aid of a syringe and needle, and a drop was placed on a clean pre-warmed slide $\left(37^{\circ} \mathrm{c}\right)$ and covered with a cover slip. The motility was determined by eye estimation of the proportion of spermatozoa moving forward (motile) and those that did not move were considered non-motile.

\section{g. SPERM MORPHOLOGY}

A drop of stained sperm suspension was prepared for sperm count. This was done by a smear on a glass slide, air-dried for a maximum of 5 minutes and then visualized microscopically at a magnification of 400X. For each rat, the sperm was screened and the percentage of total abnormalities of heads (such as microcephalus, detached head, flattened head, doubled head and bent neck) and/or tails (such as coiled tail, bent tail and doubled tail) was determined (Narayana et al., 2005; Mahaneem et al., 2010). 


\section{Statistical Analysis}

The student $\mathrm{T}$ - test was used to analyze the differences between the three groups. A value of $\mathrm{p}<0.05$ was considered statistically significant. Data are presented as mean \pm standard error of mean in the result.

\section{Results}

The initial mean body weights of groups A, B and C rats were $135.6 \pm 5.77 \mathrm{~g}, 138 \pm 10.62 \mathrm{~g}$ and $135.3 \pm$ $8.68 \mathrm{~g}$ respectively. The final mean body weight (i.e at the end of the experiment) of group $\mathrm{C}$ animals was significantly higher $(230.2 \pm 10.04 \mathrm{~g})$ than Group B $(228.3 \pm 10.54 \mathrm{~g})^{\mathrm{c}}(\mathrm{p}=0.14)$ and Group A animals $(215.7 \pm$ $3.25 \mathrm{~g})^{\mathrm{c}}(\mathrm{p}=0.45)$ as shown in table 1 .

The sperm count of Group C rats was significantly higher $\left(130.5 \pm 7.50 \times 10^{6} / \mathrm{ml}\right)$ compared to Group A $(93.5$ $\left.\pm 2.50 \times 10^{6} / \mathrm{ml}\right)(\mathrm{p}=0.02)^{\mathrm{a}}$ and group B $\left(104.3 \pm 3.48 \times 10^{6} / \mathrm{ml}\right)(\mathrm{p}=0.01)^{\mathrm{a}}$ animals. Fig 1

Following 65 days of treatments, the sperm motility of honey treated Group $\mathrm{C}$ animals was significantly higher $(85 \pm 5.00 \%)$, compared to manix treated, Group B $(33.3 \pm 3.33 \%)(\mathrm{p}=0.001)^{\mathrm{a}}$ and saline treated, Group A (75 $\pm 5.00 \%)(p=0.14)^{\mathrm{c}}$ animals. Fig.2. During the analysis it was observed that sperm motility of manix treated rats, Group B, showed significant numbers of pus cells indicating a possible seminal infection by the drug administered to this group. This could have affected the motility.

Also, the sperm morphology (\% abnormality) of Group C rats was significantly better (5\%) than Group B $(8.3 \%)(p=0.11)^{\mathrm{c}}$ and Group A $(10 \%)(\mathrm{p}=\infty)$ rats. Fig. 3

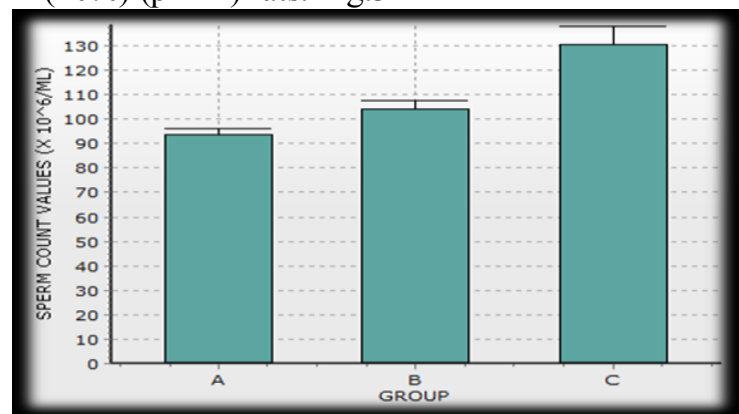

Figure 1: Effect of honey on sperm count. All data are presented as mean \pm standard error of mean, $p<0.05$ considered statistically significant. $A=$ control, $B=$ standard, $C=$ honey-treated.

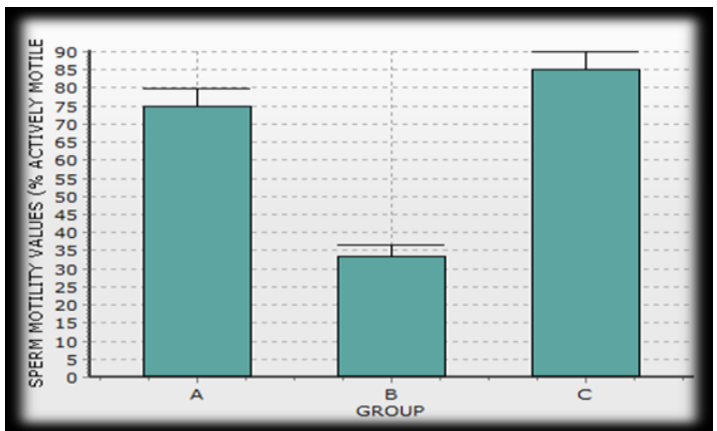

Figure 2: Effect of honey on sperm motility. All data are presented as mean \pm standard error of mean, $p<0.05$ considered statistically significant. $A=$ control, $B=$ standard, $C=$ honey-treated.

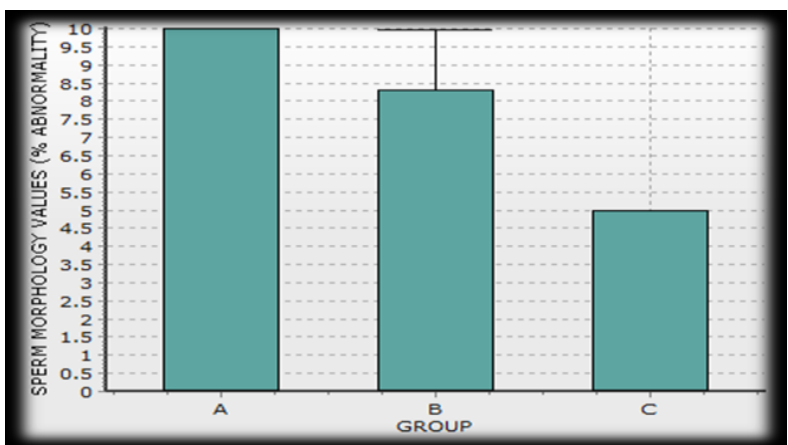

Figure 3: Effect of honey on sperm morphology. All data are presented as mean \pm standard error of mean, $p<0.05$ considered statistically significant. $A=$ control, $B=$ standard, $C=$ honey-treated. 


\section{Discussion}

In this study, it was found that the administration of honey at $1 \mathrm{ml}$ per $100 \mathrm{~g}$ of body weight increases the mean body weight of rats. This increase in weight gain might be due to the fact that honey contains carbohydrates and also has simple sugars (Ajibola et al.,2012), instead of complex carbohydrates that break down slowly.

Honey administered at a dose of $1 \mathrm{ml}$ per $100 \mathrm{~g}$ of body weight also caused increases in sperm count, sperm motility and sperm morphology in the experimental rats. Previous works done by Syanza et al., (2011), Mahaneem et al., (2010), and Abdul-Ghahi et al., (2008) on the effect of honey on sperm quality in experimental rats all concur with the results of this study in showing that honey improves the semen quality in experimental rats.

Spermatogenesis is the process of spermatozoa production and occurs within the seminiferous tubules of the testes (Johnson et al., 2000). It is regulated by paracrine and endocrine mechanisms (De Krester et al., 1998). Since spermatogenesis occurs as a result of the stimulation of testosterone (Tesarik et al., 1998), it is probable that the honey has interacted positively with luteinizing hormone, which stimulates the leydig cells to secrete more testosterone, which also explains its effect on libido. Also, honey could have interacted positively with the sertoli cells directly or indirectly through the follicle stimulating hormone to stimulate conversion of spermatids to mature spermatozoa (Syazana et al., 2011).

Abdul-Ghani et al., (2008) reported that honey increased the activities of testicular marker enzymes for spermatogenesis such as sorbitol dehydrogenase by $31 \%$ and reduced the activity of lactate dehydrogenase by 48\%. Lactate dehydrogenase has been indicated to have increased activity in infertility (Eliasson and Virji, 1985). Sorbitol dehydrogenase is an enzyme in carbohydrate metabolism converting sorbitol, the sugar alcohol form of glucose, into fructose (El-Kabbani et al., 2004). Since fructose is a component of honey and is an important marker in the seminal fluid, honey enhances sperm quality in that fructose provides energy and nutrients for the sperm and the perfect alkaline medium for the sperms to maintain their viability, thus enhancing their motility.

Honey, also known as a novel antioxidant, contains pinocembrin, pinostrobin, vitamins, glucose oxidase, diastase, (Erejuwa et al., 2012). It reduces lipid peroxidation and oxidative stress on the sperm cells by reactive oxygen species like super oxide, hydrogen peroxide, and the likes (Syazana et al., 2011).

Manix is a drug that has been invented to help boost fertility in men. The administration of this drug to the male rats showed that it might be associated with the formation of pus cells and reduced motility following prolonged use. Honey however did not exhibit such trait in its sperm boosting properties following sixty - five days of administration.

\section{Conclusion}

This study showed that administration of honey throughout the period of spermatogenesis enhanced sperm quality through improving the sperm parameters of: sperm count, sperm motility and sperm morphology. Thus honey aside from its other numerous effects, also has positive reproductive effects on the male reproductive system.

\section{Recommendation}

It is suggested that honey could be used in the place of synthetic fertility drugs in boosting fertility and treating infertility cases in men, as it poses no significant side effects. It is also recommended that more studies should be carried out on the precise mechanisms in which honey influences the gonadotropins in improving male gamete production and fertility. Studies should also be carried out on its possible effects on the female reproductive system.

\begin{tabular}{|l|l|l|l|l|}
\hline Parameters & Control Group & Standard Group & \multicolumn{1}{|c|}{ Honey Treated Group } & P value \\
\hline Initial mean body weight $(\mathrm{g})$ & $135.6 \pm 5.77$ & $138.5 \pm 10.62^{\mathrm{c}}$ & $135.3 \pm 8.68^{\mathrm{c}}$ & $<0.05$ \\
\hline Final mean body weight $(\mathrm{g})$ & $215.7 \pm 3.25$ & $228.3 \pm 10.54^{\mathrm{c}}$ & $230.2 \pm 10.04^{\mathrm{c}}$ & $<0.05$ \\
\hline Weight gain $(\mathrm{g})$ & $80.1 \pm 2.70$ & $89.8 \pm 5.29^{\mathrm{c}}$ & $94.9 \pm 4.69^{\mathrm{c}}$ & \\
\hline
\end{tabular}

Table 1. effect of honey on body weight in experimental rats after 65 days. All Data are represented as mean \pm standard error of mean, $p<0.05$ considered statistically significant. ${ }^{c}$ signifies that $p>0.05$ when compared to control group, meaning there's no significant difference.

\begin{tabular}{|l|l|l|l|l|}
\hline Group & Sperm count $\left(\mathrm{x} 10^{6} / \mathrm{ml}\right)$ & $\begin{array}{l}\text { Sperm motility } \\
\text { actively motile })\end{array}$ & $\begin{array}{l}\text { Sperm morphology }(\% \\
\text { abnormality })\end{array}$ & $\mathrm{p}$ value \\
\hline Control & $93.5 \pm 2.50$ & $75 \pm 5.00$ & $10 \pm 0.00$ & $<0.05$ \\
\hline Standard & $104.3 \pm 3.48^{\mathrm{a}}$ & $33.3 \pm 3.33^{\mathrm{a}}$ & $8.3 \pm 1.67^{\mathrm{c}}$ & $<0.05$ \\
\hline Honey treated & $130.5 \pm 7.50^{\mathrm{a}}$ & $85 \pm 5.00^{\mathrm{c}}$ & $5 \pm 0.00^{\mathrm{d}}$ & $<0.05$ \\
\hline
\end{tabular}


Table 2: effect of honey on sperm count, sperm motility and sperm morphology in experimental rats. All Data are represented as mean \pm standard error of mean, $p<0.05$ considered statistically significant.

Acknowledgement

We acknowledge the Laboratory technologists especally Mr.Joseph Egene for his efforts during the course of the project,Mr.Friday of the animal house,Bingham University.

\section{References}

[1] Johansson M, Hellström A, Berg M :Severe male infertility after failed ICSI Treatment-a phenomenological study of men's experiences Reproductive Health, :2011., vol 8 iss 4 pg 1

[2] Nygren K G and Zegers-Huchschud F : Documentation of infertility prevalence, treatment access and treatment outcomes in developing countries. Oxford Journals: ESHRE monographs. 2008, issue 1, pg 5-7.

[3] Boivin J, Bunting L, Collins J A. and Nygren K G.: International estimates of infertility prevalence and treatment-seeking: potential need and demand $\quad$ for infertility medical care. Human Reproduction 2007; Vol.22, No.6 pp. 1506-

[4] Rubeinstein J; Brannigan R.E Male infertility. Medscape reference copyright 1994-2012. All rights reserved.

[5] Mahaneem M, Sulaiman S A, Jaafar H 3, Sirajudeen K N S, Ismail Z I M and Islam N M Effect of Honey on Testicular Functions in Rats Exposed to $\quad$ Cigarette Smoke. Journal of ApiProduct and ApiMedical Science 2010; vol 3 iss 1: $\quad$ pg $12-17$

[6] Carangelo L, . Infertility cures (instead of adoption). Americans for open records. C2001, 2002 ISBN\# 0-942605-23-3. All rights reserved

[7] Bradley R. Raw Honey and Cinnamon, 2010. (c) One 80 Turn LLC.

[8] National Honey Board (2002) Honey-health and therapeutic qualities. Copyright (C) 2009 National Honey Board, All Rights Reserved

[9] Estevinho, L.; Pereira, A.; Moreira, L.; Dias, L.; Pereira, E Antioxidant and antimicrobial effects of phenolic compounds extracts of Northeast Portugalhoney. Food and Chemical Toxicology ; . 2008:.46: 3774-3779

[10] Syazana N.S., Hashida N.H., Majid A.M., Durriyyah H.A. Sharifah, Kamaruddin M.Y Effects of Gelam Honey on Sperm Quality and Testis of Rat Sains Malaysiana. ;2011: vol 40 iss 11 pg 1243-1246

[11] Tan, H.T; Halim, A.S; Hassan, S.A; Suleiman, S.A; Rahman, R.A.; Gan, S.H; Kirpin-Kaur, B.S.) antibacterial properties of Malaysian tualang honey against wound and enteric microorganisms in comparism to manuka honey.BMC complementary and Alternative Medicine. 2009, Vol 9, iss 34.

[12] Viuda-Martos, M; Navajas Y.R; Fernandez-Lopez, J; Perez-Alvarez J.A):Functional properties of honey, propolis and royal jelly. Journal of Food Science. 2005 Vol. 73, iss 9.R117-R124

[13] Manley W.: United States Standards for Grades of Extracted Honey. Agricultural marketing service. T ,1985,USDA copyrights. Iss 5 (50 FR 15861).

[14] Sikka, S C; Wang, R: Endocrine disruptors and estrogenic effects on male reproductive axis. Asian Journal of Andrology,2005.,10, 134-1S45.

[15] Skakkebaek, N.E; Giwercman, A; De-krester, D :Pathogenesis and management of male infertility. The Lancet 1994,v343, 8911.

[16]. Austin, S :Sexual performance natural supplements for boost sexual libido. Sooper articles:sexual health. Copyright $(2012$ All Rights Reserved.

[17] Abdul-Ghani AS, Dabdoub N, Muhammad R, Abdul-Ghani R, Qazzaz M. (2008) Effect of Palestinian honey on spermatogenesis in rats. Journal of Medicinal Food vol 11 iss 4 pg 799-802

[18] Ajibola .A.,Chamunorwa.J.D., and Erlwanger.K.H.: Nutraceeutical values of natural honey and its contribution to human health and wealth.Nutriton and metabolism,2012,9:6

[19] Selmanoğlu G, Hayretdağ S, Kolankaya D, Tuylu A O and Sorkun K (2009) The Effect of Pollen on Some Reproductive Parameters of Male Rats. Pestic. Phytomed. 24 Pg 59-63

[20] Biswas D; Bari, F.Y; Shamsuddin M; Rahmann M.M : Determination of glycerol percentages for preserving the black Bengal block (Capra hircus) Spermatozoa for long time. Pakistan Journal of Biological Sciences 2002, vol 5, issue; 6 pg 715-718

[21] De Krester, D M; Loveland K L; Meinhardt, A; Simorangkir D and Wreford, N :Spermatogenesis. Human Reproduction Volume 13 Supplement $11998 \mathrm{pg} 1$

[22] Tesarik, J; Guido, M; Mendoza C; Greco, E. (1998) Human spermatogenesis in vitro: Respective effects in Follicle stimulating Hormone and testosterone Meiosis, Spermiogenesis and Sertoli cell apoptosis. Journal of clinical endocrinology and metabolism. Vol 83, iss 12 , pg 4467.

[23] Eliasson R, Virji N (1985) LDH-C4 in human seminal plasma and its relationship to testicular function II. Clinical aspects. International Journal of Andrology. $\quad 8(3)$ 201-214.

[24] El- kabbani O, Darmanin C, Chung R.P.T (2004) Sorbitol dehydrogenase: structure, function and ligand design. Current medicinal chemistry. Vol 11, iss 4. Pg 465-476.

[25] Erejuwa O.O, Sulaiman S.A, Wahab M.S.A.B (2012) Honey: a novel antioxidant. Molecules 17, pg 4400-4423. 